\title{
Knowledge, awareness and prevention of cervical cancer among women attending a rural based tertiary care centre, Theni, South India
}

\author{
Shanthadevi Sambath*, Madhumitha Chandrasekaran
}

Department of Obstetrics and Gynecology, Government Theni Medical College, Theni, Tamil Nadu, India

Received: 29 November 2017

Accepted: 26 December 2017

\section{*Correspondence:}

Dr. Shanthadevi Sambath,

E-mail: devisambath@gmail.com

Copyright: (C) the author(s), publisher and licensee Medip Academy. This is an open-access article distributed under the terms of the Creative Commons Attribution Non-Commercial License, which permits unrestricted non-commercial use, distribution, and reproduction in any medium, provided the original work is properly cited.

\begin{abstract}
Background: Cervical carcinoma is the most common genital cancer in India and a leading cause of cancerassociated deaths. Cervical cancer is both preventable and curable, yet morbidity and mortality from the disease remain high especially in developing countries. Request for cervical cancer screening is exceedingly low among women due to lack of awareness of cervical cancer and the screening methods

Methods: A cross sectional study was conducted in 200 women attending Gynaecology OPD in Government Theni Medical College Hospital, Tamil Nadu. We studied the knowledge, awareness, and attitude of patients, about cervical cancer and the screening methods in a tertiary institution. They were interviewed with predesigned questionnaire after getting informed consent.

Results: Of the 200 patients surveyed, 74 (37\%) had heard of cervical cancer, while $44(22 \%)$ knew about screening, with health care providers being their most frequent source of information. Only 26 (13\%) women ever had screening done and no one is aware of HPV vaccine.

Conclusions: Adequate health information and counselling on cervical cancer and regular screening still need to be emphasized in developing countries so as to reverse the morbidity and mortality associated with cervical cancer.
\end{abstract}

Keywords: Cervical cancer, HPV vaccine, Screening

\section{INTRODUCTION}

Cervical cancer is one of the most common cancers worldwide. In India, it is one the leading causes of mortality among women accounting for $23.3 \%$ of all cancer deaths. ${ }^{1}$ India accounts for about $20 \%$ of cervical cancer cases reported from the world. More than threefourth of these patients are diagnosed in advanced stages leading to poor prospects of long term survival and cure. ${ }^{2}$ Early detection of cervical cancer is possible with various screening tests. The proportion of women who undergo Pap smear testing ranges from $68 \%$ to $84 \%$ in developed countries as compared to India where the rates range from $2.6 \%$ to $6.9 \%$ among women in communities. ${ }^{3}$ It has been found that in many developed countries the annual incidence and prevalence of cervical cancer has decreased by $50 \%-70 \%$ after introduction of population based screening. ${ }^{2}$ So if women in India undergo screening for cervical cancer, it is possible to detect the cancer in early stages thereby reducing mortality and morbidity.

India has national programme for the prevention of NonCommunicable Diseases (NCD) which includes screening for cancer cervix for all women between 30 and 60 years. The screening method followed under this programme is Visual Inspection after Acetic acid/Visual Inspection after Lugal's Iodine (VIA/VILI) followed by colposcopy in positive cases. Screening would be broadly influenced by knowledge about cervical cancer, its screening methods among women, role of health care providers who come in contact with women in hospitals, facilities available and the awareness of facilities. 
The objective of this study was to know the knowledge about cervical cancer, awareness of various cervical cancer screening methods and to explore the sources of information and the role of health care providers, among the women attending gynaecology OPD in Government Theni Medical College Hospital, Theni, Tamil Nadu, South India.

\section{METHODS}

It was a cross sectional study conducted in the months of September and October 2017. We included 200 women between 30 and 60 years of age attending Gynaecology OPD Government Theni Medical College Hospital, which is a tertiary care hospital in rural setting in Theni with more than $80 \%$ of the patients coming from surrounding rural communities.

The questionnaire was designed based on cervical cancer awareness measure toolkit version 2.1 with some modification according to our rural population. It was pretested on a sample of 30 women to check for feasibility and reliability and modified accordingly for use in the study

They were interviewed with the questionnaire after getting informed verbal consent from all participants. The study was approved by the Institution ethical committee. They were asked about the awareness of cervical cancer (Have you heard of/do you know about cervical cancer?) If the answer was 'yes', the knowledge about cervical cancer was assessed by multiple response questions, five questions for the symptoms of cancer cervix and four questions for the risk factors for cancer cervix Each response was given 1 mark. So, the maximum was nine and minimum was zero. The knowledge about cervical cancer was graded as: <4 being poor knowledge; 5-6 being satisfactory knowledge and $\geq 7$ being good knowledge.

They were also asked about the awareness of cervical cancer screening (do you know about cervical cancer screening?). If the answer was 'yes', knowledge about screening for cervical cancer was assessed with questions, whom should get tested, age of the women for the testing where and who should do the testing with maximum score of nine and the knowledge about the screening was graded as same as for knowledge about cervical cancer. They were also asked about the source of information, problems in undergoing screening and awareness about HPV vaccination. The responses were analysed with descriptive statistics for continuous variables and simple percentages for categorical variables.

After the collection of data, the women were informed about cervical cancer, the importance of its screening and facilities available for screening in the mother tongue Tamil. Implications of positive and negative results of the screening were also explained.

\section{RESULTS}

Most of the women (41\%) were between 40-50 years of age. Majority $(45 \%)$ of them were para 2 . In this study many of them are not educated, $33 \%$ of the women were illiterate, $37 \%$ cases had primary education, $20 \%$ cases had secondary education, only $3 \%$ were graduates (Table 1).

\section{Table 1: Socio demographic variables of the study population $(\mathrm{N}=\mathbf{2 0 0})$.}

\begin{tabular}{|c|c|c|c|}
\hline \multicolumn{2}{|c|}{ Demographic variables } & Number & Percentage \\
\hline \multirow{3}{*}{ Age } & $30-40$ & 50 & 25 \\
\hline & $40-50$ & 82 & 41 \\
\hline & $50-60$ & 68 & 34 \\
\hline \multirow{5}{*}{ Parity } & Nullipara & 14 & 7 \\
\hline & Para 1 & 36 & 18 \\
\hline & Para 2 & 90 & 45 \\
\hline & Para 3 & 42 & 21 \\
\hline & Para 4 & 18 & 9 \\
\hline \multirow{5}{*}{$\begin{array}{l}\text { Literacy } \\
\text { status }\end{array}$} & Illiterate & 66 & 33 \\
\hline & $\begin{array}{l}\text { Primary } \\
\text { schooling }\end{array}$ & 74 & 37 \\
\hline & Secondary & 40 & 20 \\
\hline & $\begin{array}{l}\text { Higher } \\
\text { secondary }\end{array}$ & 14 & 7 \\
\hline & Graduates & 6 & 3 \\
\hline
\end{tabular}

Table 2: Awareness about cancer cervix and its screening $(\mathbf{N}=\mathbf{2 0 0})$.

\begin{tabular}{|c|c|c|}
\hline Variables & Number & Percentage \\
\hline \multicolumn{3}{|c|}{ Ever heard about cancer cervix } \\
\hline Yes & 74 & 37 \\
\hline No & 126 & 63 \\
\hline \multicolumn{3}{|c|}{ Heard about cancer screening } \\
\hline Yes & 44 & 22 \\
\hline No & 156 & 78 \\
\hline
\end{tabular}

Table 2 shows only 74 women (37\%) had heard about cervical cancer and majority of them $(63 \%)$ had no knowledge about cancer cervix and 44 (22\%) women aware that screening is available for cancer cervix. Health care providers (doctors, nurses and other health workers) were the source of information in majority of cases (56 out of 74 women) followed by mass media (16) and social circle (2) (Table 3).

Table 3: Source of information regarding cancer cervix $(\mathrm{N}=74)$.

\begin{tabular}{|lll|}
\hline Source & Number & Percentage \\
\hline Doctor & 8 & 4 \\
\hline Nurse & 42 & 21 \\
\hline Health worker & 6 & 3 \\
\hline Media & 16 & 8 \\
\hline public & 2 & 1 \\
\hline
\end{tabular}


Majority of the women had poor knowledge about cervical cancer and its screening (Table 4). Abnormal bleeding was the symptom of carcinoma cervix and early marriage was the risk factor for cancer cervix by most of the women in this study. Only $13 \%(26 / 200)$ women had undergone screening for cervical cancer (Table 5). The common method of screening was VIA/VILI, next common method was Pap test. No one knew about the HPV vaccine for the prevention of cervical cancer.

Table 4: Grading of knowledge about cancer cervix and its screening.

\begin{tabular}{|c|c|c|}
\hline Variable & Number & Percentage \\
\hline \multicolumn{3}{|c|}{ Knowledge about cancer cervix $N=74$} \\
\hline Poor & 22 & 29.7 \\
\hline Satisfactory & 34 & 45.9 \\
\hline Good & 18 & 24.3 \\
\hline \multicolumn{3}{|c|}{ Knowledge about cervical cancer screening $N=4$} \\
\hline Poor & 20 & 45.5 \\
\hline Satisfactory & 12 & 27.3 \\
\hline Good & 12 & 27.3 \\
\hline
\end{tabular}

Table 5: Study population ever been screened for cancer cervix $\mathrm{N}=\mathbf{2 0 0}$.

\begin{tabular}{|lll|}
\hline Screening methods & Number & Percentage \\
\hline Screened & 26 & 13 \\
\hline Method used & & \\
\hline VIA /VILI & 14 & 7 \\
\hline Pap smear & 12 & 6 \\
\hline Not screened & 174 & 87 \\
\hline
\end{tabular}

Most of the participants accepted after counselling that VIA/VILI is a useful test and nearly $90 \%$ were eager for screening if given the opportunity. A significant minority (10\%) were either not decided or not willing for screening (Table 6).

Table 6: Response from study population for screening after counselling $\mathbf{N}=\mathbf{2 0 0}$.

\begin{tabular}{|lll|}
\hline Response & Number & Percentage \\
\hline Yes & 180 & 90 \\
\hline No & 10 & 5 \\
\hline Not yet decided & 10 & 5 \\
\hline
\end{tabular}

\section{DISCUSSION}

In this study even though it was conducted amongst patients attending OP for gynaecological complaints, knowledge of cancer cervix and its screening was poor. This signifies that adequate counselling is not given to the patients on both cervical cancer and screening methods.

Present study showed that only $37 \%$ of the women were aware of cervical cancer and $22 \%$ were aware of screening for cervical cancer which is similar to a study in Pondicherry where the participants are also from rural communities in south India like ours, where as in a study conducted in rural population of Kerala, almost threefourth of the study population was aware of cervical cancer and its screening. ${ }^{4,5}$ This could be probably explained by the difference in the education status of study population.

Lack of awareness about screening services, no symptoms and fear of procedure were the reason given by our women for not undergoing screening which is similar to the Kerala study. ${ }^{5}$ No one among our study population, had heard of HPV infection as a risk factor and no one knew about HPV vaccination. In a study conducted in China, $22.1 \%$ and $13.3 \%$ of the study population had heard of HPV and HPV vaccine respectively. ${ }^{6}$

The knowledge level about cervical cancer was low among the participants in spite of the introduction of National Cancer Control Programme in India. This is probably because of the lack of awareness of cervical cancer and its screening methods which is available in the nearby primary health care facilities. This signifies that adequate counselling is not given by the health care providers on both cervical cancer, screening methods and about the vaccine available to prevent cervical cancer to women attending OP which is due to heavy crowd in the OP in Government Hospitals. Also, the high incidence of cervical cancer can be reduced with introduction of national HPV vaccination programme but for the high cost of the vaccines which is not feasible in our country. ${ }^{7}$

In summary, present study population shows poor knowledge about cervical cancer and is unaware of the concept of prevention. If the women had full information on cervical cancer and its prevention and understood the importance of screening, their response to National Cancer Control Programme (NCCP) will be better. Hence, extensive health education about cervical cancer to create awareness to the public is needed which could be channelled through health facility-based talks as well as mass media including the local FM radios. ${ }^{8}$ Cervical cancer prevention campaigns should be conducted which should include husbands and local community leaders because they are essential in motivating women to participate in cervical screening programmes. ${ }^{8}$

This study has some limitations and measurement bias. It was a cross sectional study conducted among women attending a tertiary care hospital from nearby rural areas and, so it is not representative of any particular rural area. The women were of low income and less educated group and so the results may not be generalized to all women, particularly those in urban areas.

\section{CONCLUSION}

Though cervical cancer is the leading cancer among women in India, this study has shown that many women are ignorant about this completely preventable disease. 
Hence, extensive health education to the public is needed to improve their knowledge with an emphasis on the fact that both vaccination and screening are the new standards for prevention of cervical cancer, as HPV vaccination prevents most of the cervical cancer and screening can detect precancerous lesions which is curable by treatment. All women attending not only Gynaecology OP but general OP should be counselled and motivated to undergo screening for cervical cancer and informed about HPV vaccination.

Funding: No funding sources Conflict of interest: None declared

Ethical approval: The study was approved by the Institutional Ethics Committee

\section{REFERENCES}

1. World Health Organization. Globocan fact sheets. International Cancer Research. Available at http://www.globocan.iarc.fr/factsheet.asp\#WOMEN Accessed $23^{\text {rd }}$ January 2012.

2. Guidelines for cervical cancer screening. Government of India and WHO Collaborative Program. Available at http://www.whoindia.org/LinkFiles3 Accessed $23^{\text {rd }}$ January 2012.

3. Swan J, Breen N, Coates RJ, Rimer BK, Lee NC. Progress in cancer screening practices in the United States. Results from the 2000 national health interview survey. Cancer. 2003;97:1528-40.

4. Siddharthar J, Rajkumar B, Deivasigamani K. Knowledge, awareness and prevention of cervical cancer among women attending a tertiary care hospital in Puducherry, India. J Clin Diagn Res. 2014;8(6):OC01-3.
5. Aswathy S, Quereshi MA, Kurian B, Leelamoni K. Cervical cancer screening: current knowledge and practice among women in a rural population of Kerala, India. Indian J Med Res. 2012;136(2):20510.

6. Mwaka AD, Orach CG, Were EM, Lyratzopoulos G, Wabinga H, Roland M. Awareness of cervical cancer risk factors and symptoms: cross-sectional community survey in post-conflict northern Uganda. Health Expectations. 2016;19(4):854-67.

7. Fasanu AO, Akindele RA, Adebimpe WA, Ala OOA, Omopariola SO, Adisa OP. Knowledge of risk factors and utilization of cervical cancer screening services among health care workers in a Teaching Hospital in Southwestern Nigeria. Int $\mathbf{J}$ Med Med Sci. 2014;4(5):172-7.

8. Hong Y, Zhang C, Li X, Lin D, Liu Y. HPV and cervical cancer related knowledge, awareness and testing behaviors in a community sample of female sex workers in China. BMC Public Health. 2013;13(1):696.

9. Elit L, Jimenez W, McAlpine J, Ghatage P, Miller D, Plante M. Cervical cancer prevention in low-resource settings. SOGC-GOC-SCC joint policy statement. J Obstet Gynaecol Can. 2011;33(3):272-9.

10. Onwudiwe EN. Motivations and preferences of rural Nigerian women undergoing cervical cancer screening via visual inspection with acetic acid. Int $\mathbf{J}$ Gynaecol Obstet. 2013;120:262-5.

Cite this article as: Sambath S, Chandrasekaran M. Knowledge, awareness and prevention of cervical cancer among women attending a rural based tertiary care centre, Theni, South India. Int J Reprod Contracept Obstet Gynecol 2018;7:608-11. 